\title{
Editorial
}

\section{On the pitfalls of disclosure statements}

Disclosure statements are now such standard procedure for scientific journals that it is difficult to remember a time when they were not required. So it is interesting to see disclosure and transparency up for debate again in the medical literature, with some recent editorials raising concerns over the pitfalls of disclosure ${ }^{(1-8)}$. In this Public Health Nutrition (PHN) editorial we describe two instances that bring some of these pitfalls to light.

\section{Is there bias against authors with conflicts of interest to disclose?}

Last June, we accepted a paper by Luiten et al. titled 'Ultra-processed foods have the worst nutrient profile, yet they are the most available packaged products in a sample of New Zealand supermarkets' ${ }^{(9)}$. (Disclosure: Dr Waterlander, an author on the paper, is a member of the PHN Editorial Board. In accordance with journal policy, she was not involved in the peer review process or in any decisions related to the article.) The paper generated some media attention in New Zealand ${ }^{(10,11)}$ and elsewhere ${ }^{(12)}$. Not surprisingly, the paper also drew the attention of the New Zealand Food \& Grocery Council (FGC) and soon after the paper's publication we received a letter from the FGC's Chief Executive Officer, Ms Rich ${ }^{(13)}$.

In this case, Ms Rich disclosed her conflict of interest and raised valid concerns about the study's methodology. It was a straightforward decision, therefore, to follow standard journal policy and invite the authors of the original article to submit a rebuttal ${ }^{(14)}$, allowing the exchange to serve as a form of scientific debate. The subsequent submission of a letter from Dr Mackerras, the Chief Public Health Nutrition Officer at Food Standards Australia New Zealand (FSANZ), reiterated some of the same methodological concerns ${ }^{(15)}$ and confirmed the value of addressing those concerns in detail.

Instead of a letter with a simpler review process, what if Ms Rich had submitted an article for full peer review? Would it have received closer scrutiny or been met with greater scepticism than an article received by an author without such a conflict of interest? The answer is a likely yes.

From the point of view of objectivity, this would seem to be a bad thing. We like to think of scientific and peer review processes as fair, objective and unbiased, since bias distorts our ability to conduct and evaluate research. In research conducted by Kesselheim et al. ${ }^{(16)}$, physicians rated the methodology of industry-funded trials less highly than that of National Institutes of Health-funded trials, even though the trials were the same. This has raised concerns that such bias limits the publication of legitimately valuable research funded by industry ${ }^{(2)}$.

On the other hand, closer scrutiny and greater scepticism are good things if they are warranted. Systematic reviews have shown that industry-funded studies produce findings more favourable to industry ${ }^{(17-19)}$. Past experience with tobacco, fossil fuel, as well as food corporations also suggests that closer scrutiny and scepticism are warranted, since much industry effort has been put into conducting or funding research designed to deflect attention and create doubt or designed for marketing purposes.

Historian of science Allan M. Brandt ${ }^{(20)}$ has argued that current industry-academic conflicts of interest stem from strategies developed by tobacco companies:

'[John W.] Hill [president of the public relations firm for the tobacco industry in the 1950s] understood that simply denying emerging scientific facts would be a losing game [...] Hill advised that the companies should now associate themselves as great supporters of science. [...] What better strategy than to identify, solicit, support, and amplify the views of skeptics of the causal relationship between smoking and disease? [...] The goal, according to Hill, would be to build and broadcast a major scientific controversy. The public must get the message that the issue of the bealth effects of smoking remains an open question. Doubt, uncertainty, and the truism that there is more to know would become the industry's collective new mantra.'

The same 'playbook' comes to mind when reading about sceptics of climate change ${ }^{(21,22)}$. Comparisons with the food industry are also inevitable, and they bring to light some uncomfortable similarities between tobacco and food corporations' responses to threats to their profit $\operatorname{margin}^{(23)}$. A recent historical document analysis implicates the sugar industry in the same strategy, describing in detail its efforts to 'deflect attention' from the benefits of restricting sugar intake ${ }^{(24)}$. In her recent book, Marion Nestle clearly and comprehensively exposes both the 'softball' and 'hardball' tactics used by the soda industry to prevent any measures that could discourage soda sales, including support of health professional organizations and research $^{(25)}$. Of more direct relevance to the New Zealand FGC, Ms Rich has been implicated in paying for social media attacks on public health academics in New Zealand ${ }^{(26)}$. Moreover, the fact that Ms Rich went on 
to publish her $P H N$ letter on an FGC website that called the Luiten et al. article 'another disappointing example of food politicking dressed up as academic research' ${ }^{\text {(27) }}$ does not inspire confidence that this industry entity is ready to engage in scientific disagreement without resorting to name-calling.

In sum, closer scrutiny and greater scepticism are a justifiable consequence of industry actions in the past. In this case, the disclosure statement did what it was supposed to - trigger concerns and raise red flags.

As a side note, we were concerned that the methodological issues raised by Ms Rich and Ms Mackerras from FSANZ should have been caught during the review process and perhaps were missed because the findings confirmed what the reviewers hoped or expected. In this case, however, the comments raised by the three reviewers appeared to be quite balanced overall. The points raised by Ms Rich and Ms Mackerras were perhaps only obvious to people who were very familiar with and invested in the scoring system used in the paper. Our concern about 'confirmation bias' in the review process relates to the possible role of undisclosed, ideological interests - a second pitfall of disclosure statements.

\section{When does 'having no conflicts of interest to declare' really mean having no conflicts of interest?}

A second article that also generated some controversy raises the question of what kinds of competing interests should be disclosed. The paper by Gillie ${ }^{(28)}$ aimed to refute the findings of two articles published in the Lancet that found no evidence that vitamin D supplementation reduces risk of disease ${ }^{(29,30)}$. (Disclosure: $\mathrm{Mr}$ Gillie is a former member of the $P H N$ Editorial Board. Again, in accordance with journal policy, Mr Gillie was not involved in the peer review process or in any decisions related to the article.) Mr Gillie's original disclosure stated, 'I have no conflicts of interest. I have worked on vitamin D and sunshine issues for more than 10 years without funding.' In response to a reader's query, $\mathrm{Mr}$ Gillie subsequently revised his statement ${ }^{(31)}$, revealing minimal financial interests but a record of commitment to vitamin D research, and his advocacy on behalf of it.

Advocacy per se is not the same as bias, but the fact that Mr Gillie did not include his advocacy work in his initial disclosure statement demonstrates the difficulty of recognizing our own potential conflicts of interest. As stated in $P H N$ 's Conflict of Interest Policy, 'Financial relationships such as research support, employment, consultancies, or honoraria, are the most easily identifiable conflicts of interest. However, non-financial conflicts can also exist as a result of personal relationships, academic competition, political, ideological, religious, or scientific preconceptions, and organizational or institutional affiliations.' These non-financial interests are the hardest to recognize. They are ubiquitous, as no researcher is completely objective $^{(32)}$. Yet there exists almost no guidance on what level of academic, intellectual or ideological interest merits declaration. As a result, many, perhaps even most, nonfinancial interests probably go undeclared.

\section{Avoiding the pitfalls}

If disclosure policies can lead to bias against an article or to unwarranted complacency, then they clearly are not a 'panacea' ${ }^{,(8)}$. But disclosure is recognized by leading bodies on publication ethics as critical to dealing with conflicts of interest ${ }^{(33-35)}$. Disclosure offers readers a glimpse into some of the competing interests that might underlie an author's perspective and the opportunity to evaluate the author's methods and conclusions in that light.

Is there anything we can do to avoid the pitfalls? One thing is this: every study should be read with close scrutiny, even scepticism, whether a competing interest is disclosed or not. In this sense, disclosure statements merely serve as reminders that we should not let down our guards, even if the study confirms what we hoped it would and even if the authors state that they have "no conflicts of interest to disclose'. When unwarranted bias and complacency are the possible pitfalls of reading disclosure statements, it becomes clear that disclosure statements do not eliminate the need for judgement or critical evaluation on the part of the reader.

Second: to be critical readers, we need to recognize our own interests and biases. As public health nutrition researchers and practitioners, we are and should be passionate about our beliefs and causes. But $P H N$ is a scholarly journal devoted to 'the publication and dissemination of research and scholarship', adhering to the highest standards of peer review. The cases raised in this editorial emphasize to us, and we hope to you as readers, the importance of reflecting on our own potential biases and the possible ways to identify and keep them in check when dealing with scholarly research - particularly when its results may be opposite to our beliefs.

Marilyn Tseng Editor-in-Chief

Allison Hodge
Carl Lachat
Stefanie Vandevijvere
Eduardo Villamor
Deputy Editors

\section{References}

1. Drazen JM (2015) Revisiting the commercial-academic interface. $N$ Engl J Med 372, 1853-1854. 
2. Rosenbaum L (2015) Understanding bias - the case for careful study. N Engl J Med 372, 1959-1963.

3. Rosenbaum L (2015) Beyond moral outrage - weighing the trade-offs of COI regulation. N Engl J Med 372, 2064-2068.

4. Chew M, Brizzell C, Abbasi K et al. (2014) Medical journals and industry ties. BMJ 349, g7197.

5. Godlee F (2015) Authors' reply to Smith, Forsyth, Coffey and Prendergast, and Soskolne. BMJ 350, h42.

6. Horton R (2015) Offline: the BMJ vs $N E J M$ - lessons for us all. Lancet 385, 2238.

7. Abbasi K (2014) Why transparency isn't an unassailable philosophical principle. J R Soc Med 107, 215.

8. Wilson M (2014) Is transparency really a panacea? $J R$ Soc Med 107, 216-217.

9. Luiten CM, Steenhuis IHM, Eyles H et al. (2016) Ultraprocessed foods have the worst nutrient profile, yet they are the most available packaged products in a sample of New Zealand supermarkets. Public Health Nutr 19, 530-538,

10. Fairfax New Zealand Limited (2015) NZ packaged food ultra-processed, unhealthy. Stuff, 30 July 2015. http:// www.stuff.co.nz/national/health/70642530/nz-packagedfood-ultraprocessed-unhealthy (accessed November 2015).

11. Scoop Media (2015) Majority of our packaged foods unhealthy. Scoop Independent News, 30 July 2015. http:// www.scoop.co.nz/stories/GE1507/S00131/majority-of-ourpackaged-foods-unhealthy.htm (accessed November 2015).

12. Xinhua, english.news.cn (2015) New Zealand supermarkets stocking 'unhealthiest food available': study. Xinhua News, 30 July 2015. http://news.xinhuanet.com/english/2015-07/30/c_134464084.htm (accessed November 2015).

13. Rich K (2015) Comment on: 'Ultra-processed foods have the worst nutrient profile, yet they are the most available packaged products in a sample of New Zealand supermarkets' by Luiten et al. (Letter to the Editor). Public Health Nutr 19, 564-569.

14. Waterlander WE, Luiten CM, Eyles H et al. (2015) Response to two Letters to the Editor: we maintain that ultra-processed supermarket foods are less healthy than their minimally processed counterparts (Letter to the Editor). Public Health Nutr 19, 571-573.

15. Mackerras D (2015) Comment on Luiten et al.'s paper: 'Ultra-processed foods have the worst nutrient profile, yet they are the most available packaged products in a sample of New Zealand supermarkets' (Letter to the Editor). Public Health Nutr 19, 570.

16. Kesselheim AS, Robertson CT, Myers JA et al. (2012) A randomized study of how physicians interpret research funding disclosures. $N$ Engl J Med 367, 1119-1127.

17. Lesser LI, Ebbeling CB, Goozner M et al. (2007) Relationship between funding source and conclusion among nutritionrelated scientific articles. PLOS Med $\mathbf{4}$, e5.

18. Bes-Rastrollo M, Schulze MB, Ruiz-Canela M et al. (2013) Financial conflicts of interest and reporting bias regarding the association between sugar-sweetened beverages and weight gain: a systematic review of systematic reviews. PLOS Med 10, e1001578.
19. Massougbodji J, Le Bodo Y, Fratu R et al. (2014) Reviews examining sugar-sweetened beverages and body weight: correlates of their quality and conclusions. Am J Clin Nutr 99, 1096-1104.

20. Brandt AM (2012) Inventing conflicts of interest: a history of tobacco industry tactics. Am J Public Health 102, 63-71.

21. Oreskes N \& Conway EM (2010) Merchants of Doubt. New York: Bloomsbury Press.

22. Gillis J \& Schwartz J (2015) Deeper ties to corporate cash for doubtful climate researcher. The New York Times, 21 February 2015. http://www.nytimes.com/2015/02/22/ us/ties-to-corporate-cash-for-climate-change-researcher-WeiHock-Soon.html (accessed November 2015).

23. Brownell KD \& Warner KE (2009) The perils of ignoring history: Big Tobacco played dirty and millions died. How similar is Big Food? Milbank Q 87, 259-294.

24. Kearns CE, Glantz SA \& Schmidt LA (2015) Sugar industry influence on the scientific agenda of the National Institute of Dental Research's 1971 National Caries Program: a historical analysis of internal documents. PLOS Med 12, e1001798.

25. Nestle M (2015) Soda Politics: Taking on Big Soda (and Winning). New York: Oxford University Press.

26. Hager N (2014) Dirty Politics: How Attack Politics Is Poisoning New Zealand's Political Environment. Nelson, NZ: Craig Potton Publishing.

27. New Zealand Food \& Grocery Council (2015) More food activist research from Auckland University. http://www.fgc. org.nz/media/more-food-activist-research-from-aucklanduniversity (accessed November 2015).

28. Gillie O (2015) Controlled trials of vitamin D, causality and type 2 statistical error. Public Health Nutr 19, 409-414

29. Autier PBM, Pizot C \& Mullie P (2013) Vitamin D status and ill health: a systematic review. Lancet Diabetes Endocrinol 2, 76-89.

30. Bolland MJ, Grey A, Gamble GD et al. (2014) The effect of vitamin D supplementation on skeletal, vascular, or cancer outcomes: a trial sequential meta-analysis. Lancet Diabetes Endocrinol 2, 307-320.

31. Gillie O (2015) Vitamin D, causation, conflict of interest, and other issues - Corrigendum. Public Health Nutr 19, 415-416.

32. Rothman K (1993) Conflict of interest: the new McCarthyism in science. JAMA 269, 2782-2784.

33. Fletcher R \& Ferris L, the WAME Publication Ethics and Editorial Policy Committees (2009) Conflict of interest in peer-reviewed medical journals. http://www.wame.org/ about/conflict-of-interest-in-peer-reviewed-medical (accessed December 2015).

34. Committee on Publication Ethics (2015) COPE consultation/ guidance document on handling competing interests. http:// publicationethics.org/forum-discussion-topic-comments-please-5 (accessed December 2015).

35. International Committee of Medical Journal Editors (2015) Author responsibilities - conflicts of interest. http://www.icmje. org/recommendations/browse/roles-and-responsibilities/ author-responsibilities-conflicts-of-interest.html (accessed December 2015). 